\title{
CORRELATIONS BETWEEN NETWORK VULNERABILITY AND LAPLACIAN ENERGIES
}

\author{
*Mehmet Ali BALCI, Department of Mathematics, Faculty of Science, Muğla Sitkı Koçman University, Turkey, \\ mehmetalibalci@mu.edu.tr \\ (iD) https://orcid.org/0000-0002-4650-8294) \\ Ömer AKGÜLLER, Department of Mathematics, Faculty of Science, Muğla Sitkı Koçman University, Turkey, \\ oakguller@mu.edu.tr \\ (iD https://orcid.org/0000-0002-7061-2534) \\ Erva KOL, Department of Mathematics, Faculty of Science, Muğla Sıtkı Koçman University, Turkey, \\ ervakol@hotmail.com \\ https://orcid.org/0000-0002-1825-0097) \\ Received: 25.08.2019, Accepted: 04.10.2019 \\ *Corresponding author

\begin{abstract}
In the network analysis, vulnerability plays key role. Similarly, Laplacian matrices are also effective tools in network analysis. In this study, we examine correlations between those two concepts. We first calculate the well-known vulnerability measures called edge connectivity, vertex connectivity, and solitude number. Then, we find correlation between vulnerability measures and energies of Laplacian matrices. As a result, we find strong correlations between Laplacian energies and vertex connectivity of a network.
\end{abstract}

Keywords: Network analysis, Network vulnerability, Laplacian, Graph energies

\section{AĞ KIRILGANLIĞI VE LAPLASYEN ENERJİLER ARASINDAKİ KORELASYONLAR}

\section{Özet}

Ağ analizinde kırılganlık kavramı önemli rol oynamaktadır. Benzer şekilde, Laplasyen matrisleri de ağ analizinde etkili araçlardır. Bu çalışmada, bu iki kavram arasındaki korelasyon incelenmiştir. İlk olarak, oldukça çok bilinen ayrıt bağlantılık, tepe bağlantılık ve yalnızlık sayıları hesaplanmıştır. Daha sonra, bu kırılganlık ölçüleri ile Laplasyen matrislerinin enerjileri arasındaki korelasyon hesaplanmıştır. Sonuç olarak, bir ağın Laplasyen enerjileri ile tepe bağlantılık ölçüsü arasında güçlü korelasyonlar bulunmuştur.

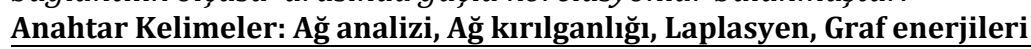

Cite

Balcı, M.A., Akgüller, Ö., Kol, E. (2019). “Correlations Between Network Vulnerability and Laplacian Energies”, Mugla Journal of Science and Technology, 5(2), 73-76.

\section{Introduction}

A network structure consists of connection lines that provide communication between nodes. Network design is based on continuity of communication. For any communication network, the durability of the network despite the interruptions that occur in certain nodes or connection lines is called the vulnerability measurement of the network. Networks with greater vulnerability are more stable $[1,2,3,4,5]$. Communication networks can be modeled with graphs such that the nodes are the vertices of the graph and the connecting lines are the edges of the graph. Therefore, in order to examine the stability structure of a network, it is sufficient to examine the vulnerability measures over the graph structure that models the network. Vulnerability measurements are used in a network structure to determine the strength of the network. At the same time, these measurements enable the selection of the most stable structure for the continuity of data communication among alternative graph models used in designing a network. The greater the vulnerability measurements, the more stable the graph indicates. Only the solitude number is the opposite of these measurements [6]. In other words, graph structures with smaller solitude number are more stable. In this study, vertex connectivity, edge connectivity, and solitude number vulnerability measurements were examined.

The concept of energy originates from chemistry and refers to the willingness of atoms to form molecules together. Since the bond formed by the atoms forming stable molecules is strong, the energies of such molecules are also high. In Hückel Molecular Orbital Theory, an area of theoretical chemistry, the Hückel energy of a conjugated hydrocarbon (carbon atoms saturated with hydrogen) is given as the sum of the energies of pi and 
sigma electrons. The formulated form thereof is as follows:

$$
\mathcal{E}_{i}=n \alpha+m \beta
$$

In the formula $\alpha$ and $\beta$ Hückel molecular orbital constants, $n$ and $m$ are real numbers. The $n \alpha$ value used to calculate the Hückel energy gives the sum of the energies of the sigma electrons and the $m \beta$ gives the sum of the energies of the pi electrons $[7,8]$.

For any $A \in M_{m, n}$ define the energy of $A, \varepsilon(A)$,

$$
\varepsilon(A)=\sum_{i=1}^{m} s_{i}(A)
$$

If the $M$ matrix is a square matrix, the graph energy of the $M$ matrix is calculated as follows:

$$
E_{M}(G)=\sum_{i=1}^{n}\left|\mu_{i}-\bar{\mu}\right|,
$$

where $\mu_{1}, \ldots, \mu_{n}$ are the eigenvalues of $M$ and $\bar{\mu}$ is the average of $\mu_{1}, \ldots, \mu_{n}$. If $M$ is the adjacency matrix $A(G)$, then $\bar{\mu}=0$.

The aim of this study is to determine correlation between the vulnerability measures and graph Laplacian energies. Graph Laplacian is discrete analogues of the continuous Laplacian, and encodes information about the shape of a graph. There are several graph Laplacian definitions [9]. Rest of the paper is as follows: In Section 2, we give basic definitions on several vulnerability measures, graph Laplacians and energies. Then, in Section 3, we present computational results. Finally, in Section 4, we give concluding remarks.

\section{Preliminaries}

Definition 1. [10] Let $G$ be a simple, connected graph and $S \subseteq V$. If $G-S$ is not conneted, $S$ is called the vertex cut cluster. The vertex-connected value of the graph is the number of elements of the cluster with the minimum cardinality out of all possible vertex cut sets and is defined as

$$
k(G)=\min \{|S|, S \subseteq V\}
$$

Definition 2. [10] Let $\mathrm{G}$ be a simple, connected graph and $T \subseteq E$. If $G-T$ is not conneted, $T$ is called the edge cut cluster. The edge-connected value of the graph, is defined as

$$
k^{\prime}(G)=\min \{|T|, T \subseteq E\}
$$

Definition 3. [11] For a $G$ graph, $m$ is the number of components of the graph (G-S), the toughness value of this graph, is defined as

$$
t(G)=\min _{S \subseteq V}\left\{\frac{|S|}{m(G-S)}\right\}
$$

Definition 4. [12] $\mathrm{S} \subseteq \mathrm{V}$, the integrity value of a $\mathrm{G}$ graph, is defined as

$$
\mathcal{J}(G)=\min _{S \subseteq V}\{|S|+m(G-S)\} .
$$

Definition 5. [13] Let iso $(G)$ of isolated vertices formed by subtraction of vertices from the graph. The solitude number of a simple and combined $\mathrm{G}$ graph, is defined as

$$
S(G)=\frac{\sum_{i=1}^{n-1} \sum_{j=i+1}^{n}\left|i z_{i, j}(G)\right|}{\left(\begin{array}{c}
n \\
2
\end{array}\right)} .
$$

Definition 6. The degree matrix of , $D(G)$, is an $n \times n$ diagonal matrix such that $D(G)_{i i}=d_{i}$,where $d_{i}$ is the degree of vertex $v_{i}$

Definition 7. [14] The Laplacian matrix of a graph, $L(G)$, is defined as $L(G)=D(G)-A(G)$, where $\mathrm{D}(G)$ is the degree matrix, and $A(G)$ is the adjacency matrix of $G$.

The Laplacian matrix is both a positive semidefinite and an $M$-matrix [15]. Since the sum of the degrees of vertices of a graph $G$ is $2 m$, we note that the trace of $L(G)$ is $2 m$. Therefore, the mean of its eigenvalues is $\frac{2 m}{n}$.

Definition 8. Let $\mu_{1}, \mu_{2}, \ldots, \mu_{n}$ be the eigenvalues of $L(G)$. Then the Laplacian energy, $\operatorname{LE}(\mathrm{G})$, is defined as

$$
L E(G)=\sum_{i=1}^{n}\left|\mu_{i}-\frac{2 m}{n}\right| .
$$

Definition 9. The sign-less Laplacian matrix of a graph, $L^{+}(G)$, is defined as $L^{+}(G)=D(G)+A(G)$, where $\mathrm{D}(G)$ is the degree matrix, and $A(G)$ is the adjacency matrix of $G$ [7]. Thus, the entries of the sign-less Laplacian matrix equal the absolute values of those in the Laplacian matrix.

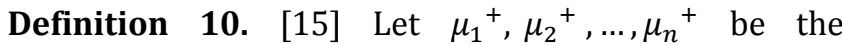
eigenvalues of $L^{+}(G)$. Then the sign-less Laplacian energy, $L E^{+}(G)$, is defined as

$$
L E^{+}(G)=\sum_{i=1}^{n}\left|\mu_{i}^{+}-\frac{2 m}{n}\right|
$$

Definition 11. Let the transition matrix of a random walker on the graph $P=D^{-1} A$. A graph of random walk normalized Laplacian, is defined as

$$
L^{R W}=D^{-1} L=D^{-1}(D-A)=I-P
$$

where $I$, is unit matrix. For any graph, random walk Laplacian defined as $L^{R W}=\pi(I-P)$, where $\pi$ is a scalar number [16].

Definition 12. Let $\mu_{1}{ }^{R W}, \mu_{2}{ }^{R W}, \ldots, \mu_{n}{ }^{R W}$ be the eigenvalues of $L^{R W}(G)$. Then the random walk Laplacian energy, $L E^{R W}(G)$, is defined as

$$
L E^{R W}(G)=\sum_{i=1}^{n}\left|\mu_{i}^{R W}-\frac{2 m}{n}\right|
$$

\section{Computational Results}

In order to determine the correlation between the graph vulnerabilities and Laplacian energies, we first examine non-isomorphic simple graphs with 50 vertices. The vertex degree distributions of the graphs are presented in Fig 1. 


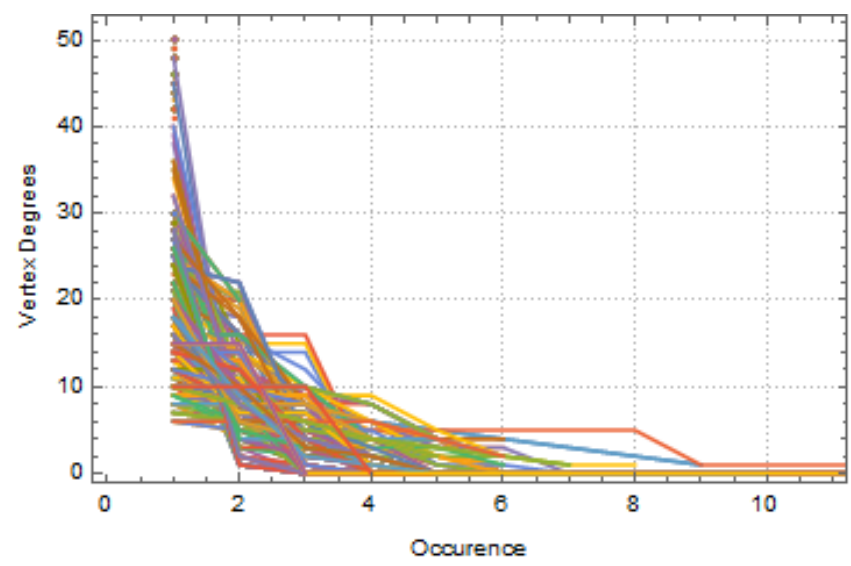

Figure 1. Vertex degree distributions

In order to obtain correlations, we first compute edge connectivity, vertex connectivity and solitude number of each graphs, then compare those vulnerability measures with energies of Laplacian, sign-less Laplacian, and random walk Laplacian.

The density plots of vulnerability measures and Laplacian energies are presented in Fig 2.
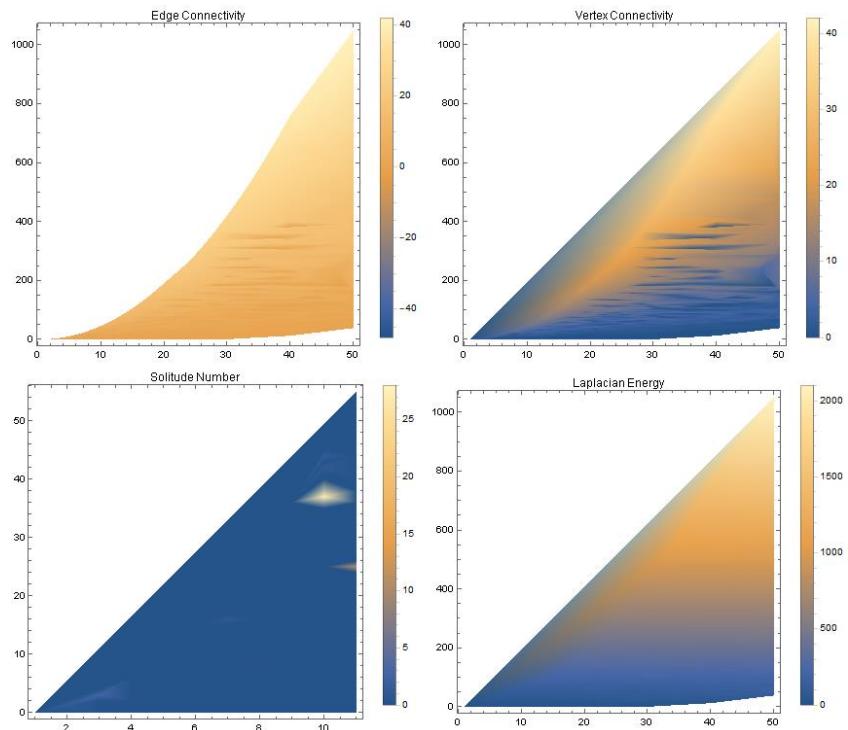

Figure 2. Vulnerability measures and Laplacian energies

The density plots of vulnerability measures and sign-less Laplacian energies are presented in Fig 3.
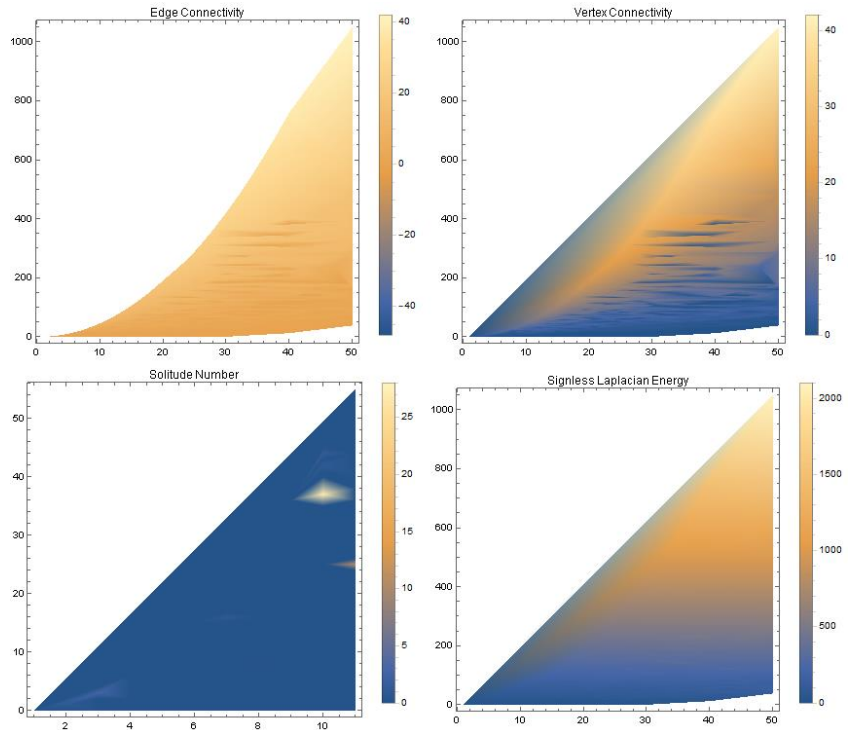

Figure 3. Vulnerability measures and signless Laplacian energies

The density plots of vulnerability measures and random walk Laplacian energies are presented in Fig 4.
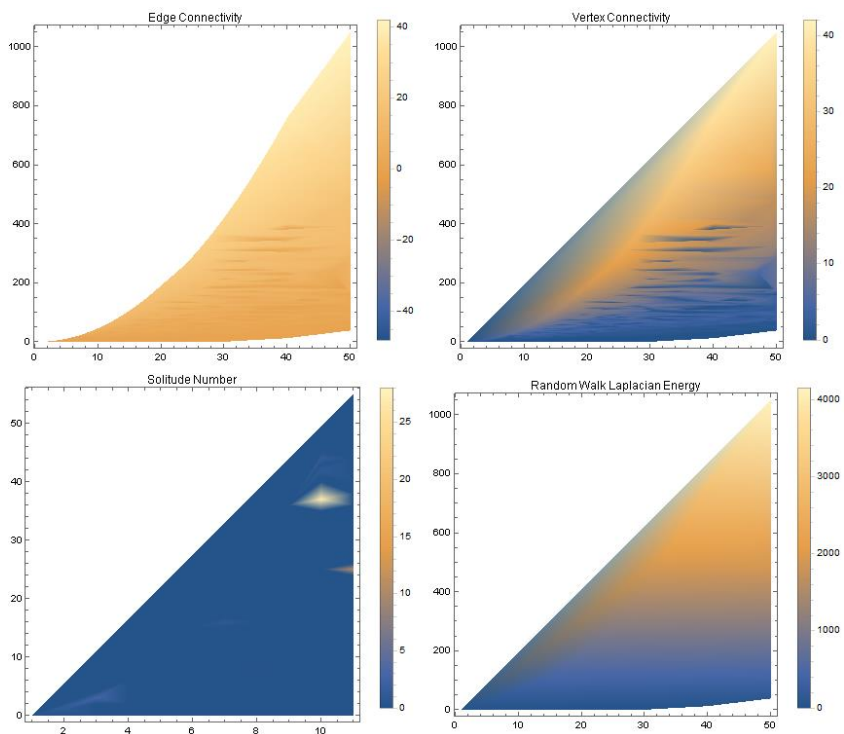

Figure 4. Vulnerability measures and random walk Laplacian energies

From Fig 2-4, it is straightforward that there are strong positive correlation between the vertex connectivity and all Laplacian energies. However, there are no correlation between the solitude number and Laplacian energies. Besides, there are no correlation also between the edge connectivity and Laplacian energies. In Tab 1, we present the cross correlations between those values. 
Table 1. Cross Correlations

\begin{tabular}{|l|c|c|c|}
\hline & $\begin{array}{l}\text { Laplacian } \\
\text { Energy }\end{array}$ & $\begin{array}{l}\text { Signless } \\
\text { Laplacian } \\
\text { Energy }\end{array}$ & $\begin{array}{l}\text { Random } \\
\text { Walk } \\
\text { Laplacian } \\
\text { Energy }\end{array}$ \\
\hline $\begin{array}{l}\text { Edge } \\
\text { Connectivity }\end{array}$ & 0.011 & 0.011 & 0.01 \\
\hline $\begin{array}{l}\text { Vertex } \\
\text { Connectivity }\end{array}$ & 0.887 & 0.886 & 0.902 \\
\hline Solitude & -0.131 & -0.131 & -0.119 \\
\hline
\end{tabular}

\section{Conclusions}

Vulnerability emerges as a strong measure for network analysis and design. There are several types of vulnerability measures defined in literature. Most common ones are vertex and edge connectivity measures. Besides, there is a vulnerability measure called solitude number which measures stability of a graph model. Another important topic emerges for network analysis is Laplacian. Network Laplacian encodes information about the shape of a graph.

In this study, we present cross correlation between these two important topics. In order to present cross correlations, we examined the energies of Laplacian, sign-less Laplacian, and random walk Laplacian of a simple graph.

Our results show that there is strong correlation between the vertex connectivity and all types of Laplacians. We also show that there are very weak positive correlations between edge connectivity and Laplacian energies. Similarly, we show that there are very weak negative correlations between solitude number and Laplacian energies.

Regarding to our findings, we may conclude that the shape of a network is only correlated to its stability by the means of vertex measures.

\section{References}

[1] Holme, P., Kim, B. J., Yoon, C. N. and Han, S. K. “Attack vulnerability of complex networks". Physical review E, 65(5), 056109. 2002

[2] Durgun, D. D. and Bagarathan A. "On the average covering number of pyramid and circular ladder graphs". Advanced Mathematical Models \& Applications. 3(3), 206-210, 2018

[3] Durgun, D. D. and Lökçü, B. "Strong domination number of some graphs". Celal Bayar Üniversitesi Fen Bilimleri Dergisi, 11(2), 2015

[4] Doğan, D. "Average lower domination number of some graphs". International Journal of Mathematical Combinatorics. 4, 58-67, 2012

[5] Durgun, D. D. and Bagatarhan, A. "Average covering number for some graphs". RAIRO-Operations Research, 53(1), 261-268, 2019
[6] Ammann, P., Wijesekera, D. and Kaushik, S. "Scalable, graph-based network vulnerability analysis". In Proceedings of the 9th ACM Conference on Computer and Communications Security (pp. 217-224). ACM., 2002

[7] Gutman, I. 1The energy of a graph: old and new results1. In Algebraic combinatorics and applications (pp. 196-211). Springer, Berlin, Heidelberg, 2001

[8] Hoffmann, R. "An extended Hückel theory. I. hydrocarbons". The Journal of Chemical Physics, 39(6), 1397-1412, 1963

[9] Pirzada, S. and Ganie, H. A. “On the construction of Lequienergetic graphs". AKCE International Journal of Graphs and Combinatorics, 12(2-3), 141-154, 2015

[10] Diestel, R. "Graph theory". Graduate Texts in Math, 101, 2005

[11] Chvátal, V. "Tough graphs and hamiltonian circuits". Discrete Mathematics, 5(3), 215-228, 1973

[12] Bagga, K. S., Beineke, L. W., Lipman, M. J. and Pippert, R. E. "Edge-integrity: a survey". Discrete mathematics, 124(1-3), 3-12, 1994

[13] Guler, H., Dundar, P. and Balci, M. A. "Solitude number at graphs". IJ Pure and Applied Mathematics, 66(3), 355-364, 2011

[14] Grone, R., Merris, R. and Sunder, V. S. "The Laplacian spectrum of a graph". SIAM Journal on Matrix Analysis and Applications, 11(2), 218-238, 1990

[15] Das, K. C. and Mojallal, S. A. "Relation between energy and (signless) Laplacian energy of graphs". MATCH Commun. Math. Comput. Chem, 74(2), 359-366, 2015

[16] Boley, D., Ranjan, G. and Zhang, Z. L. "Commute times for a directed graph using an asymmetric Laplacian". Linear Algebra and its Applications, 435(2), 224-242, 2011 